Research

\title{
Onset of relief of dyspnoea with budesonide/formoterol or salbutamol following methacholine-induced severe bronchoconstriction in adults with asthma: a double-blind, placebo-controlled study
}

\author{
René E Jonkers*1, Theo A Bantje ${ }^{2}$ and René Aalbers ${ }^{3}$
}

Address: ${ }^{1}$ Department of Pulmonary Diseases, Academic Medical Centre, Amsterdam, The Netherlands, ${ }^{2}$ Department of Pulmonary Diseases, Amphia Ziekenhuis, Breda, The Netherlands and ${ }^{3}$ Department of Pulmonary Diseases, Martini Hospital, Groningen, The Netherlands

Email: René E Jonkers* - R.E.Jonkers@amc.uva.nl; Theo A Bantje - TBantje@Amphia.nl; René Aalbers - r.aalbers@MZH.nl

* Corresponding author

Published: 04 December 2006

Respiratory Research 2006, 7:141 doi:10.1|86/1465-992I-7-14|
Received: 29 June 2006

Accepted: 04 December 2006

This article is available from: http://respiratory-research.com/content/7////4I

(C) 2006 Jonkers et al; licensee BioMed Central Ltd.

This is an Open Access article distributed under the terms of the Creative Commons Attribution License (http://creativecommons.org/licenses/by/2.0), which permits unrestricted use, distribution, and reproduction in any medium, provided the original work is properly cited.

\begin{abstract}
Background: The long-acting $\beta_{2}$-agonist (LABA) formoterol has an onset of effect comparable to that of salbutamol. Consequently, the combination of formoterol and budesonide in one inhaler, approved for maintenance use, can potentially be used for reliever therapy. This study compared the onset of relief from induced bronchospasm with a single dose of budesonide/formoterol versus standard salbutamol therapy in patients with asthma.

Methods: In this randomised, double-blind, placebo-controlled, cross-over study, 32 patients with asthma underwent a methacholine provocation test leading to a fall in forced expiratory volume in I second (FEV $)$ of $\geq 30 \%$ at enrolment (Visit I) and three subsequent study visits (Visits 2-4). Immediately after each provocation at Visits 2-4, patients received one of three test treatments: one inhalation of budesonide/ formoterol 160/4.5 $\mu \mathrm{g}$ (via Turbuhaler ${ }^{\circledR}$ ), two inhalations of salbutamol $100 \mu \mathrm{g}$ (via a pressurised metereddose inhaler [PMDI]) or placebo. All patients received each of the test treatments in a randomised order, after separate methacholine provocations. The effect of treatment on FEV and breathlessness (using the Borg scale) was measured at I, 3, 5, 10, 15, 20, 25 and 30 minutes after test treatment.

Results: Following methacholine provocation, Borg score increased from a baseline value of below 0.5 to 3.03, $3.3 \mathrm{I}$ and 3.50 before treatment with budesonide/formoterol, salbutamol and placebo, respectively. Budesonide/formoterol and salbutamol reversed methacholine-induced dyspnoea (breathlessness) rapidly. At I minute after inhalation, statistically significant decreases in Borg score were observed for budesonide/ formoterol and salbutamol ( $p=0.0233$ and $p<0.000$ I, respectively, versus placebo), with similar rapid increases in $\mathrm{FEV}_{1}$ (both active treatments $\mathrm{p}<0.000 \mathrm{I}$ versus placebo). The median time to $50 \%$ recovery in Borg score after methacholine provocation was 3 minutes with budesonide/formoterol, 2 minutes with salbutamol and 10 minutes with placebo. All treatments and procedures were well tolerated.

Conclusion: Single doses of budesonide/formoterol and salbutamol both provided rapid relief of dyspnoea and reversal of severe airway obstruction in patients with asthma with experimentally induced bronchoconstriction. The perception of relief, as confirmed by objective lung function assessment, provides evidence that budesonide/formoterol can be used as reliever medication in asthma.
\end{abstract}




\section{Background}

For many years, short-acting $\beta_{2}$-agonists (SABA), such as salbutamol and terbutaline, have played an important role in the treatment of asthma; the bronchodilating effects have, indeed, proved to be life-saving for episodes of acute asthma. The long-acting $\beta_{2}$-agonist (LABA) formoterol has a comparable onset of action to salbutamol and terbutaline, based upon objective lung measurements such as forced expiratory volume in 1 second $\left(\mathrm{FEV}_{1}\right)$ [1-7]. Furthermore, as-needed formoterol provides superior asthma control compared with terbutaline [6] and salbutamol $[7,8]$. The rapid onset of action and long duration of effect of formoterol are now acknowledged in asthma treatment guidelines [9].

The combination of budesonide and formoterol in one inhaler improves asthma control compared with a similar or higher dose of inhaled corticosteroid (ICS) [10-13]. Moreover, the rapid onset of effect of formoterol suggests that budesonide/formoterol is suitable for both maintenance and reliever therapy, i.e. without the need for a separate SABA. Clinical studies show that use of budesonide/ formoterol for both maintenance and reliever therapy provides additional improvements in asthma control (assessed by symptoms and exacerbations) over the same maintenance therapy plus SABA for relief $[14,15]$. The effectiveness of this novel regimen, where patients use budesonide/formoterol as their only reliever medication, is thought to be the result of early intervention with rapid increases in ICS dose at the first signs of symptoms $[16,17]$.

One potential concern with as-needed budesonide/formoterol use is that patients switching from a SABA to budesonide/formoterol as reliever medication may fail to achieve similarly rapid relief of their symptoms. The efficacies of high-dose formoterol $[5,18]$ and budesonide/ formoterol $[19,20]$ have been demonstrated in patients with acute asthma. To date, however, no studies have demonstrated whether the lowest dose of formoterol in budesonide/formoterol (i.e. 160/4.5 $\mu \mathrm{g}$ administered via the dry-powder inhaler Turbuhaler ${ }^{\oplus}$ ), provides a similar onset of efficacy as a standard dose of salbutamol in a situation of acute severe bronchospasm. This was assessed in the present study, which compared the onset of effect of a single dose of budesonide/formoterol with two $100 \mu \mathrm{g}$ inhalations of salbutamol (administered via a pressurised metered-dose inhaler [pMDI]) for relieving dyspnoea (breathlessness) in patients with acute asthma symptoms provoked by methacholine challenge.

\section{Methods}

\section{Study population}

Patients were required to fulfil the following inclusion criteria: male or female outpatients aged between 18 and 50 years (inclusive), with asthma for a minimum of 6 months (American Thoracic Society definition [21]) prior to Visit 1 ; a baseline $\mathrm{FEV}_{1}$ of $>1.5 \mathrm{~L}$ and $>60 \%$ of predicted normal [22]; a provocative concentration of methacholine causing a $20 \%$ fall in $\mathrm{FEV}_{1}\left(\mathrm{PC}_{20}-\mathrm{MCh}\right) \leq 8 \mathrm{mg} /$ $\mathrm{mL}$ and a demonstrated fall in $\mathrm{FEV}_{1}$ of $>30 \%$ upon continuation of the provocation test; ability to inhale correctly through Turbuhaler ${ }^{\circledR}$ and pMDI inhalers.

Patients were excluded from the study if, within 6 weeks prior to Visit 1, they had used oral, rectal or intravenous corticosteroids or if they had experienced an asthma exacerbation or a change in ICS dose. Female patients who were pregnant, planning pregnancy, breastfeeding or not using an adequate method of contraception (as judged by the investigator) were also excluded. Other exclusion criteria included the use of $\beta$-blocker therapy (including eye drops) and any significant disease or disorder that might either put the patient at risk because of participation in the study or negatively influence the patient's ability to participate in the study.

Patients were asked to avoid strenuous exercise for 2 hours, smoking for 1 hour and consumption of caffeinecontaining beverages for 8 hours before clinic visits (Visits 1-4) and until all study-related procedures had been completed at the visit.

The study protocol and informed consent form were approved by an independent ethics committee. The study was performed in accordance with the Declaration of Helsinki. Informed consent was obtained from all patients.

\section{Study design}

This randomised, double-blind, double-dummy, placebocontrolled, crossover study (study code D5890C0007) was conducted at three centres in The Netherlands. The study comprised an initial enrolment visit (Visit 1) and three study visits (Visits 2, 3 and 4), with each visit separated by 3-14 days. Prior to each visit patients were required to withdraw from bronchodilator medication. At each visit patients underwent a methacholine provocation test, using the 2-minute tidal breathing method [22], leading to a fall from baseline in $\mathrm{FEV}_{1}$ of $\geq 30 \%$. The methacholine test was only performed if the patient's $\mathrm{FEV}_{1}$ at baseline, prior to commencing the test, was $>1.5 \mathrm{~L}$, differed by not more than $\pm 15 \%$ from the Visit 1 value and was $>60 \%$ of predicted normal. The same methacholine provocation method was used in all centres.

Patients were randomised at Visit 2. At Visits 2-4, immediately following the methacholine provocation test, active and double-dummy placebo treatments were administered in accordance with the randomisation schedule: one inhalation of budesonide/formoterol 160/ 
$4.5 \mu \mathrm{g}$ (via Turbuhaler ${ }^{\circledR}$ ), two inhalations of salbutamol $100 \mu \mathrm{g}$ (via pMDI) or placebo. Half of the patients took their first inhalation from the Turbuhaler ${ }^{\circledast}$, the other half used the pMDI first. All test medications were inhaled within 1 minute of the last methacholine dose. FEV 1 was measured and patients graded their breathlessness using the Borg scale $[23,24]$ during the provocation test and at $1,3,5,10,15,20,25$ and 30 minutes after administration of the study drug.

\section{Methods of assessment}

$\mathrm{FEV}_{1}$ was measured by spirometry according to the European Respiratory Society guidelines [25]. The Borg score was used to provide a measure of patients' perception of dyspnoea [24,25]. Patients were instructed on how to perform the Borg score assessment and then asked (in Dutch): 'Please indicate the level of breathlessness that you are feeling at this exact moment by choosing the appropriate number on the scale in front of you'. Patients estimated the intensity of breathlessness by selecting a score ranging from 0 to 10 , with 0 indicating no appreciable breathlessness and 10 indicating maximal tolerable sensation.

Adverse events, both spontaneously reported and in response to two standard questions ('Have you had any health problems since the last visit?' and 'Have you had any health problems since you were last asked?'), were assessed at Visits 2-4, upon arrival at the clinic and before departure (after the methacholine provocation test).

\section{Statistical analysis}

The primary efficacy outcome variable was the change in Borg score, which was defined as the difference between the Borg score obtained at the end of the methacholine provocation test (before drug intake) and the Borg score obtained at 1 minute after drug administration. Secondary outcome variables included change in $\mathrm{FEV}_{1}$ measurement at 1 minute, time to recovery in Borg score $(50 \%$ decrease from the post-methacholine value) and time to recovery in $\mathrm{FEV}_{1}$ (return to $85 \%$ of the baseline $\mathrm{FEV}_{1}$ value).

The statistical analysis was performed at AstraZeneca R \& D Lund, Sweden using Gauss from Aptech Systems Inc. and the Riemann Library (Gauss kernel revision 6.0.40; Riemann Library version 2.3.0). The mean change in Borg score from the end of the provocation test to 1 minute after study drug administration was analysed using an additive analysis of variance model, with treatment, period and patient as fixed factors and with the Borg score before drug intake (i.e. obtained at the end of the provocation test) as a covariate. Mean changes in Borg score were estimated and 95\% confidence intervals were calculated.
The mean change in $\mathrm{FEV}_{1}$ was expressed as the ratio between the $\mathrm{FEV}_{1} 1$ minute after study drug administration and the $\mathrm{FEV}_{1}$ before drug intake (i.e. from the end of the provocation test). A multiplicative analysis of variance model with patient, period and treatment as fixed factors and $\mathrm{FEV}_{1}$ before drug intake as a covariate was used to analyse the mean change in $\mathrm{FEV}_{1}$. Geometric mean ratios in $\mathrm{FEV}_{1}$ were estimated and 95\% confidence intervals were calculated.

Times to recovery in Borg score and FEV $_{1}$ after drug administration were illustrated graphically using the Kaplan-Meier technique. Statistical analyses of time to recovery for Borg score and $\mathrm{FEV}_{1}$ were performed in separate Cox proportional hazards models stratified by patient and with treatment as factor. In addition, pairwise comparisons were performed using the Wilcoxon signed rank test. Recovery times were interpolated from the measurements of Borg score and $\mathrm{FEV}_{1}$ after drug administration. Adverse events were described using frequency and percentages.

\section{Results}

A total of 44 patients were enrolled in the study, 32 of whom were randomised to treatment. The safety analysis included all 32 randomised patients; however, one patient (lost to follow-up) completed only one period of treatment (placebo), hence the efficacy analysis is based on 31 patients. The study design and a summary of patient flow throughout the study are shown in Figure 1. A summary of demographic and clinical data for the 32 randomised patients is presented in Table 1.

\section{Efficacy}

Borg dyspnoea score increased from a baseline value of below 0.5 to post-provocation values of $3.03,3.31$ and 3.50 before administration of budesonide/formoterol, salbutamol and placebo, respectively. A trend towards a

\section{Table I: Patient baseline demographics}

\begin{tabular}{lc}
\hline Characteristic & Patients $(\mathbf{n}=\mathbf{3 2})$ \\
\hline Sex & 15 \\
Male & 17 \\
$\quad$ Female & $33.5[18-50]$ \\
Mean age, years [range] & $14[1-48]$ \\
Median time since asthma diagnosis, years [range] & 29 \\
ICS use & \\
$\quad$ Patients, $\mathrm{n}$ & $677[100-2000]$ \\
$\quad$ Mean daily dose, $\mu$ [range] & $3.40[1.83-5.22]$ \\
Mean FEV, L [range] & $93.6[6 \mathrm{I}-126]$ \\
Mean FEV $_{1}, \%$ predicted normal [range] & $0.47[0.1-6.7]$ \\
Mean $^{\mathrm{a}} \mathrm{PC}_{20}, \mathrm{mg} / \mathrm{mL}$ [range] &
\end{tabular}

aGeometric mean.

Abbreviations: ICS = inhaled corticosteriod, $\mathrm{FEV}_{\mathrm{I}}=$ forced expiratory volume in I second; $\mathrm{PC}_{20}=$ provocative concentration of methacholine causing a $20 \%$ fall in $\mathrm{FEV}_{\mathrm{l}}$. 


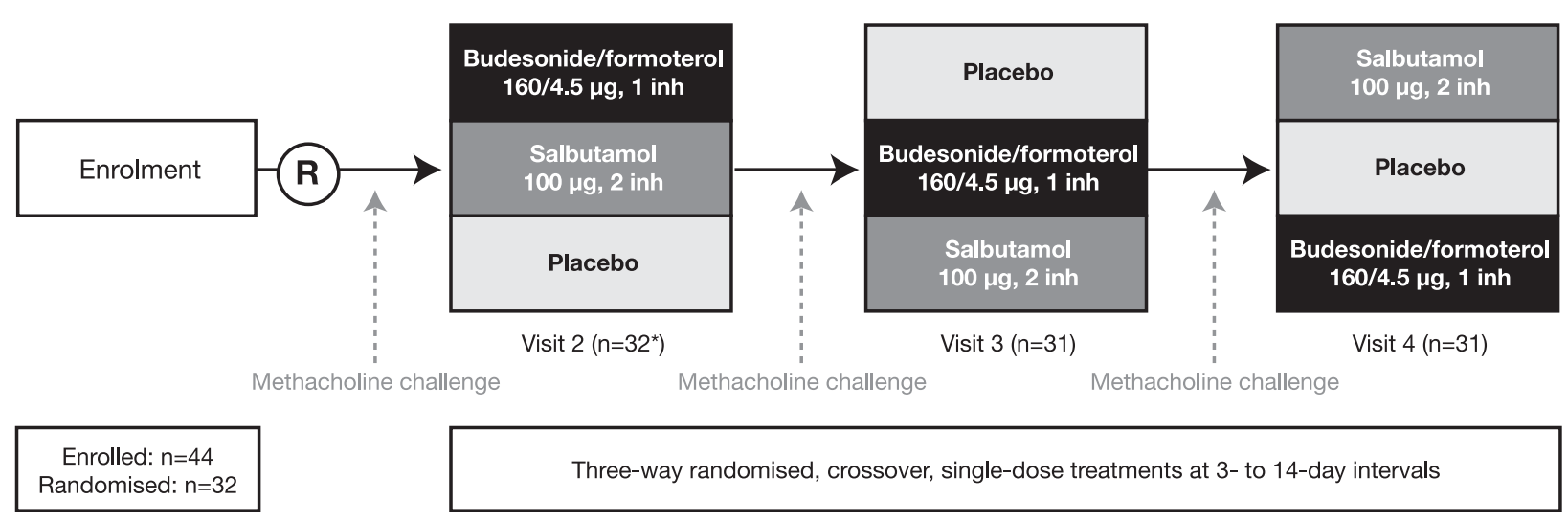

*Includes 1 patient who was lost to follow-up after first treatment (placebo); all 32 treated patients were included in the safety analysis. Abbreviation: inh = inhalations.

Figure I

Study design and patient flow.

smaller increase in Borg score was observed on the budesonide/formoterol days as compared with the salbutamol and placebo days (Figure 2; Table 2). Both budesonide/ formoterol and salbutamol reversed methacholineinduced dyspnoea rapidly. At 1 minute after inhalation, a greater decrease in Borg score was observed for both budesonide/formoterol and salbutamol compared with placebo $(-0.89$ and -1.31 versus -0.46 , respectively; $\mathrm{p}=$ 0.0233 and $\mathrm{p}<0.0001$, respectively, versus placebo). A statistically significant difference in favour of salbutamol was observed between the two active treatments at the 1minute observation (mean change -0.41 for salbutamol versus budesonide/formoterol; $\mathrm{p}=0.024$ ).

Between 3 and 30 minutes post-treatment, mean Borg scores decreased at a similar rate with budesonide/formot- erol and salbutamol. A spontaneous slow recovery in Borg score was observed following inhalation of placebo, but placebo scores were always approximately double those seen after inhalation of budesonide/formoterol and salbutamol.

The median time to 50\% recovery in Borg score was similar for budesonide/formoterol and salbutamol (3 and 2 minutes, respectively; $\mathrm{p}=0.1413$ ), and significantly longer for placebo (10 minutes; $\mathrm{p}=0.0028$ and $\mathrm{p}<$ 0.0001 for budesonide/formoterol and salbutamol, respectively, versus placebo) (Figure 3 ).

$\mathrm{FEV}_{1}$ decreased rapidly from a pre-provocation value of approximately $3.25 \mathrm{~L}$ to approximately $2 \mathrm{~L}$ in all three treatment periods during methacholine provocation

Table 2: Methacholine provocation test data

\begin{tabular}{lccc}
\hline Assessment & Budesonide/formoterol $(n=3 I)$ & Salbutamol $(n=3 I)$ & Placebo $(n=3 I)$ \\
\hline $\mathrm{FEV}_{1}, \mathrm{~L}$ [range] & & & \\
$\quad$ Before provocation & $3.27[1.78-4.93]$ & $3.22[1.83-4.98]$ & $3.25[1.83-5.1 \mathrm{I}]$ \\
$\quad$ After provocation & $2.14[1.24-3.40]$ & $1.99[1.10-3.13]$ & $2.03[1.05-3.49]$ \\
$\mathrm{PC}_{20}, \mathrm{mg} / \mathrm{ml}$ [range] & $0.42[0.08-5.8 \mathrm{I}]$ & $0.44[0.06-4.66]$ & $0.46[0.07-8.64]$ \\
Borg score ${ }^{\mathrm{a}}$ after provocation & $3.03[1.0-5.0]$ & $3.31[0.5-7.0]$ & $3.50[0.5-7.0]$ \\
[range] & & &
\end{tabular}

All data are presented as geometric means, apart from Borg scores, which are arithmetic means.

aBorg dyspnoea scores subjectively measure perceived breathlessness on a scale $0-10$, where $0=$ nothing at all and $10=$ maximal breathlessness. 


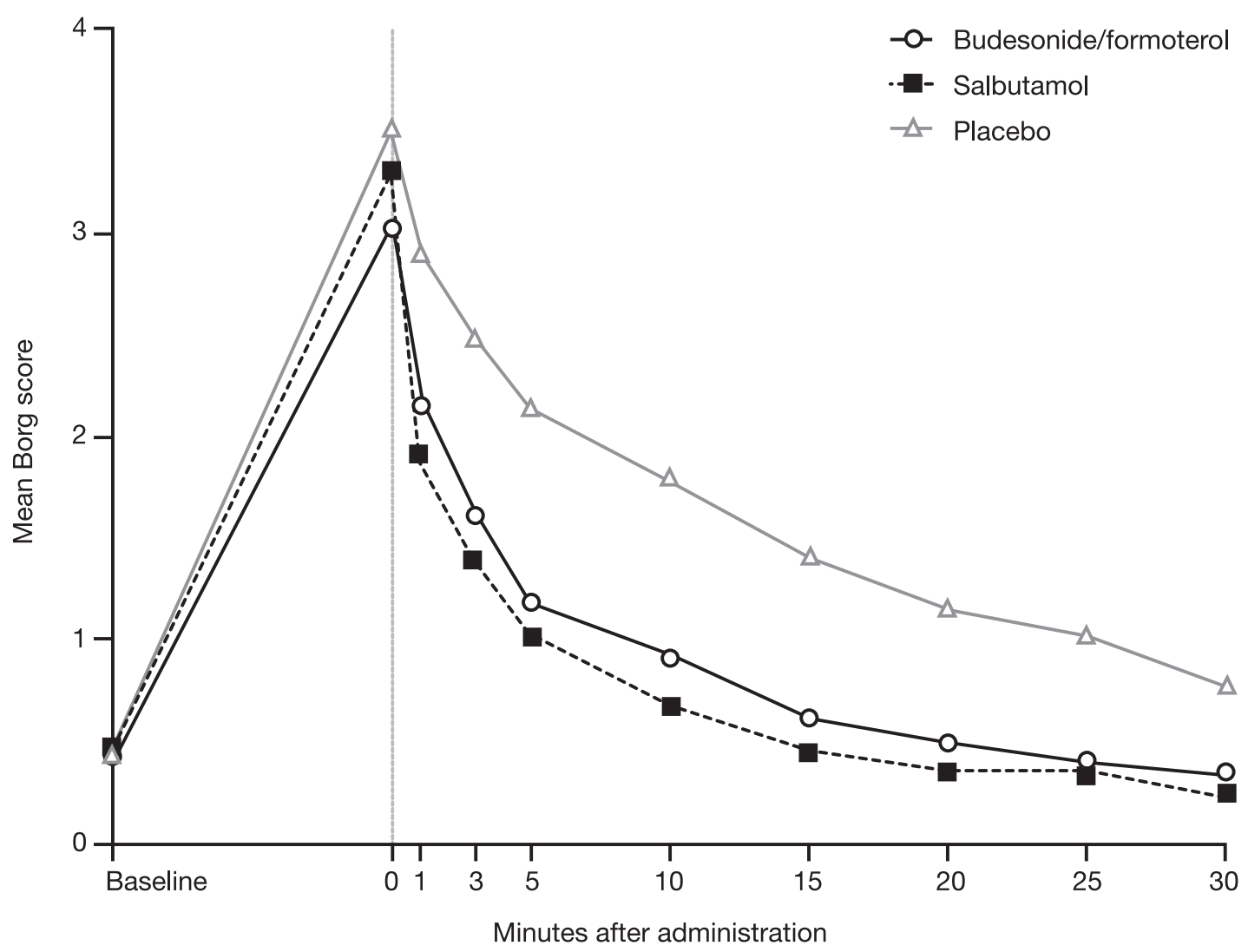

\section{Figure 2}

Mean Borg score for patients with asthma after methacholine challenge (time $=0$ ) and at various timepoints after one inhalation of one of the following as reliever medication: budesonide/formoterol 160/4.5 $\mu \mathrm{g}$ (via Turbuhaler ${ }^{\circledR}$ ), salbutamol I00 $\mu \mathrm{g}$ (via pressurised metered-dose inhaler [PMDI]) or placebo.

(Table 2; Figure 4). The reduction in $\mathrm{FEV}_{1}$ was smaller before administration of budesonide/formoterol compared with salbutamol or placebo. Budesonide/formoterol and salbutamol increased $\mathrm{FEV}_{1}$ after 1 minute versus placebo (19\% and $25 \%$ versus $6 \%$, respectively; both $\mathrm{p}<$ 0.0001 ) (Figure 4). This corresponds to a difference of $0.30 \mathrm{~L}$ for budesonide/formoterol and $0.39 \mathrm{~L}$ for salbutamol versus placebo; the corresponding difference between budesonide/formoterol and salbutamol was $0.09 \mathrm{~L}(\mathrm{p}=$ $0.0309)$. Over the entire remaining recovery period, similar increases in $\mathrm{FEV}_{1}$ were seen with the two active treatments.

The median time to recovery of $\mathrm{FEV}_{1}$ to $85 \%$ of baseline (which corresponds to approximately half the metha- choline-induced fall) was similar for budesonide/formoterol and salbutamol (3.7 and 3.2 minutes, respectively; $\mathrm{p}$ $=0.1977$; Figure 5), but significantly longer for placebo (22 minutes; $\mathrm{p}<0.0001$ for both budesonide/formoterol and salbutamol versus placebo) (Figure 5).

\section{Safety}

Study procedures and treatments were well tolerated. Adverse events were few in number, of mild to moderate intensity and similar in reported pattern following all three test treatments. No serious adverse events were reported and no events led to study discontinuation. Adverse events often associated with $\beta$-adrenoceptor agonist therapy were few in number: palpitations were reported for one patient during salbutamol treatment; 


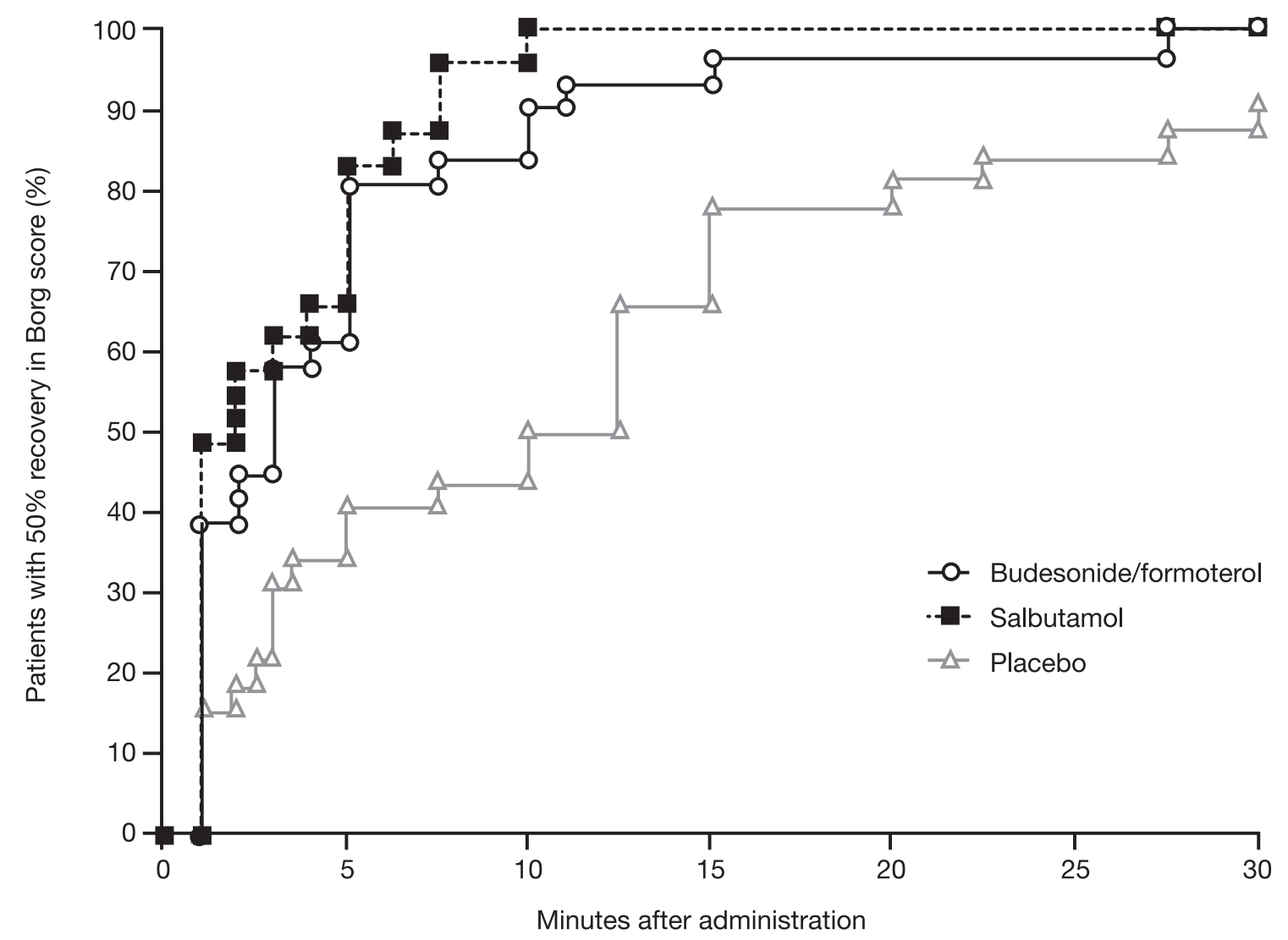

Figure 3

Kaplan-Meier plot for time to $50 \%$ recovery from methacholine-provoked increases in Borg dyspnoea score in patients with asthma taking one inhalation of one of the following for reliever medication: budesonide/formoterol I60/4.5 $\mu \mathrm{g}$ (via Turbuhaler $^{\circledR}$ ), salbutamol $100 \mu \mathrm{g}$ (via pressurised metered-dose inhaler [PMDI]) or placebo. Reliever medication was given immediately after methacholine challenge.

headache was reported for one patient receiving budesonide/formoterol and for one patient receiving placebo treatment.

\section{Discussion}

The aim of this study was to compare the onset of relief of dyspnoea provided by a single dose of budesonide/formoterol with a standard two dose administration of salbutamol in an experimental human model of severe acute bronchoconstriction. Both budesonide/formoterol (160/ $4.5 \mu \mathrm{g}$ one inhalation) and salbutamol (100 $\mu \mathrm{g}$ two inhalations) were superior to placebo for the primary efficacy variable - the onset of relief of dyspnoea, expressed as the change in Borg score 1 minute after study drug adminis- tration. A similarly rapid effect on $\mathrm{FEV}_{1}$ was observed at 1 minute after inhalation of the active treatments, confirming that patients perceive the rapid relief of bronchoconstriction with both active treatments (budesonide/ formoterol and salbutamol) and that the perception of relief is mirrored by objective measurements of lung function.

Both budesonide/formoterol and standard salbutamol treatment resulted in rapid improvements in lung function within the first minutes after inhalation that returned to near baseline levels within 20 minutes. The median time to $50 \%$ recovery in dyspnoea and reversal of the fall in $\mathrm{FEV}_{1}$ were similar, approximately 2-3 minutes for both 


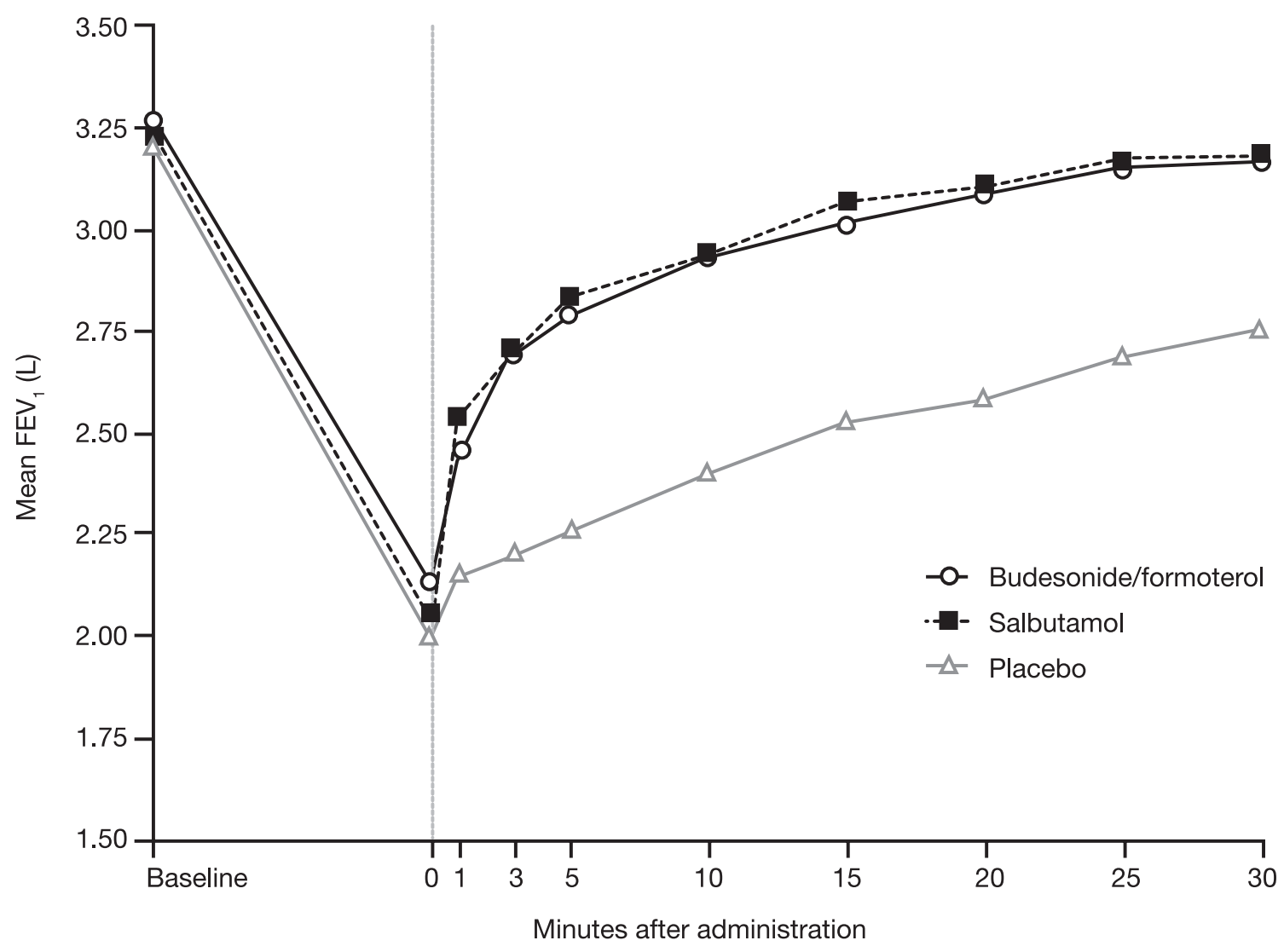

Abbreviations: $\mathrm{FEV}_{1}=$ forced expiratory volume in 1 second.

\section{Figure 4}

Mean FEV , for patients with asthma after methacholine challenge (time $=0$ ) and at various timepoints after one inhalation of one of the following as reliever medication: budesonide/formoterol 160/4.5 $\mu \mathrm{g}$ (via Turbuhaler ${ }^{\circledR}$ ), salbutamol I00 $\mu \mathrm{g}$ (via pressurised metered-dose inhaler [PMDI]) or placebo.

active treatments for dyspnoea and 3-4 minutes for $\mathrm{FEV}_{1}$, with no detectable or clinically relevant difference between the active treatments for either parameter. In contrast, both active treatments achieved reversal of the fall in $\mathrm{FEV}_{1} \geq 18$ minutes ahead of placebo and dyspnoea relief $\geq 7$ minutes ahead of placebo. Differences in Borg score and $\mathrm{FEV}_{1}$ after the first minute favoured the salbutamol regimen, but were not present thereafter. However, the effect of methacholine on Borg score and $\mathrm{FEV}_{1}$ was slightly less on the test days prior to budesonide/formoterol administration. Therefore, the window for recovery was slightly smaller for the combination therapy. Previous studies comparing formoterol and salbutamol showed similar effects for the two drugs [1-5]. Thus, the small differences seen at 1 minute in this study may in part be related to the study procedures and differences in baseline conditions.

Both budesonide/formoterol and salbutamol were well tolerated and the adverse events reported raised no safety concerns. The few adverse events that were reported were mild or moderate in intensity and occurred with a comparable frequency following placebo and active treatments.

The bronchoconstriction induced by methacholine is solely due to the contraction of airway smooth muscle 


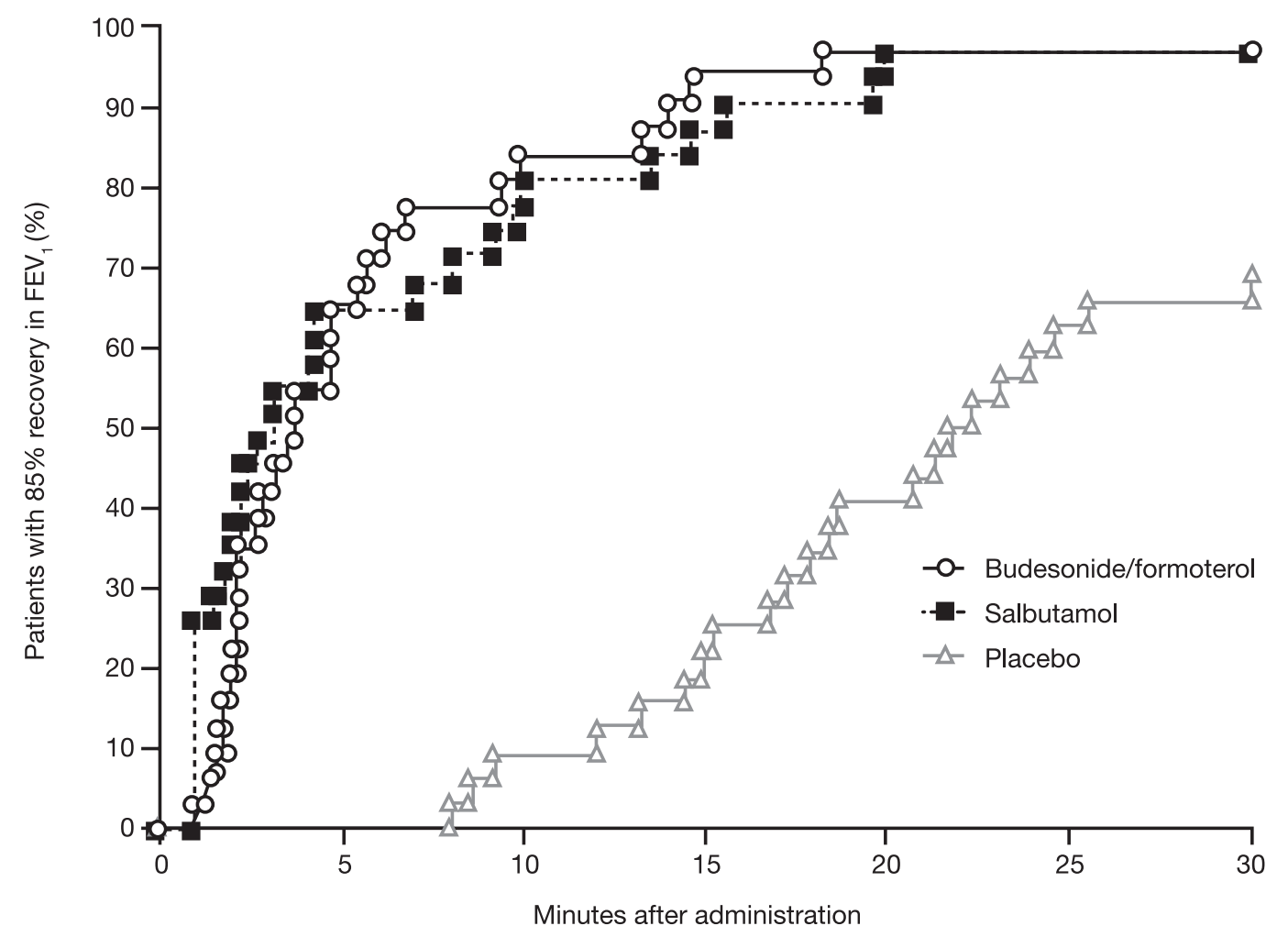

Abbreviations: $\mathrm{FEV}_{1}=$ forced expiratory volume in 1 second.

\section{Figure 5}

Kaplan-Meier plot for time to recovery to $85 \%$ of baseline FEVI values obtained prior to induced bronchospasm in patients with asthma following one inhalation of one of the following as reliever medication: budesonide/formoterol $160 / 4.5 \mu g$ (via Turbuhaler $^{\circledR}$ ), salbutamol $100 \mu \mathrm{g}$ (via pressurised metered-dose inhaler [PMDI]) or placebo. Reliever medication was given immediately after methacholine challenge.

cells and is, therefore, considered an appropriate model in which to investigate the smooth muscle relaxing effects of $\beta_{2}$-agonists given as monotherapy or in ICS/LABA combinations. Both salbutamol and formoterol are known to reverse this contraction of airway smooth muscle that represents at least part of the component of airway obstruction occurring in an acute asthma exacerbation $[1,2,26,27]$. Two previous studies have shown that highdose budesonide/formoterol was as effective and well tolerated in the treatment of acute asthma in an emergency setting as high-dose salbutamol [19] or high-dose formoterol [20]. The results of our study support the findings from these two previous high-dose studies and suggest that even a low formoterol dose administered as a single inhalation of budesonide/formoterol can be used to relieve severe asthma symptoms effectively.
Although available evidence points to a similar onset and magnitude of effect for salbutamol and formoterol (either as a single component or in the budesonide/formoterol combination) in reversing acute bronchoconstriction, formoterol and, particularly, formoterol/budesonide used as both maintenance and reliever therapy may have additional advantages over salbutamol. These advantages include improved asthma control through a longer duration of bronchodilation and bronchoprotection with formoterol $[6,8]$ and a more timely adjustment in antiinflammatory therapy with extra budesonide, given at the first sign of increasing symptoms $[14,15,28,29]$.

\section{Conclusion}

Budesonide/formoterol provides rapid relief of dyspnoea in asthma patients with experimentally induced bron- 
choconstriction. The relief of bronchoconstriction as perceived by asthma patients treated with budesonide/ formoterol, confirmed by relief of objective lung function assessments, was similar to that observed with salbutamol. This suggests that the budesonide/formoterol combination is suitable for the immediate relief of asthma symptoms.

\section{Competing interests}

The study described in this manuscript was supported by AstraZeneca, who also paid the article-processing charge. The Departments of Pulmonary Diseases at the Academic Medical Centre, Amsterdam (RE Jonkers) and Martini Hospital, Groningen (R Aalbers) received unrestricted research grants from AstraZeneca for the conductance of two clinical studies. R Aalbers has provided consultancy services to AstraZeneca, GlaxoSmithKline, Merck Sharp \& Dohme and Novartis

\section{Authors' contributions}

RE Jonkers, TA Bantje and R Aalbers were involved in the design of the study, data collection, analysis and interpretation and the drafting of the paper. All authors had complete access to the study report, made final decisions on all aspects of the article and hence are in agreement with, and approve, the final version of the submitted article.

\section{Acknowledgements}

We would like to thank the following: Åsa Carlsheimer (AstraZeneca, Lund, Sweden), who provided statistical support; Tomas LG Andersson and Ulf Sjöbring (AstraZeneca, Lund, Sweden), who contributed to the interpretation of the results and the compilation of the manuscript; Martin Boorsma and Heidi Vliegenthart-de Gouw (AstraZeneca, Zoetermeer, The Netherlands), who contributed to the study design and the data collection, management and interpretation and Felicity Leigh (Adelphi Communications Ltd) who provided medical writing support on behalf of AstraZeneca.

This study (study code D5890C0007) was supported by AstraZeneca plc. AstraZeneca were involved in the study design, interpretation of the data and the decision to submit the paper for publication in conjunction with the study investigators. Employees of the sponsor collected the data, managed the data and performed the data analysis. All investigators had free and unlimited access to the Clinical Study Report and Statistical Reports. Employees of the sponsor reviewed drafts of the manuscript and made editing suggestions.

\section{References}

I. van Noord JA, Smeets IJ, Maesen FP: A comparison of the onset of action of salbutamol and formoterol in reversing methacholine-induced bronchoconstriction. Respir Med 1998, 92:|346-|35|.

2. Politiek MJ, Boorsma M, Aalbers R: Comparison of formoterol, salbutamol and salmeterol in methacholine-induced severe bronchoconstriction. Eur Respir ] 1999, 13:988-992.

3. Grembiale RD, Pelaia G, Naty S, Vatrella A, Tranfa CM, Marsico SA: Comparison of the bronchodilating effects of inhaled formoterol, salmeterol and salbutamol in asthmatic patients. Pulm Pharmacol Ther 2002, 15:463-466.

4. Seberova E, Andersson A: Oxis (formoterol given by Turbuhaler) showed as rapid an onset of action as salbutamol given by a pMDI. Respir Med 2000, 94:607-6II.
5. Boonsawat W, Charoenratanakul S, Pothirat C, Sawanyawisuth K, Seearamroongruang T, Bengtsson T, Brander R, Selroos O: Formoterol (OXIS) Turbuhaler as a rescue therapy compared with salbutamol pMDI plus spacer in patients with acute severe asthma. Respir Med 2003, 97: I067-1074.

6. Tattersfield AE, Lofdahl CG, Postma DS, Eivindson A, Schreurs AG, Rasidakis A, Ekstrom T: Comparison of formoterol and terbutaline for as-needed treatment of asthma: a randomised trial. Lancet 200I, 357:257-26I.

7. Cheung D, van Klink HC, Aalbers R, OZON study group: Improved lung function and symptom control with formoterol on demand in asthma. Eur Respir J 2006, 27:504-5 I0.

8. Pauwels RA, Sears MR, Campbell M, Villasante $C$, Huang $S$, Lindh $A$, Petermann W, Aubier M, Schwabe G, Bengtsson T, RELIEF Study Investigators: Formoterol as relief medication in asthma: a worldwide safety and effectiveness trial. Eur Respir J 2003, 22:787-794.

9. Global Initiative for Asthma: Global strategy for asthma management and prevention - updated 2005. Hamilton: Global Initiative for Asthma 2005.

10. Zetterström O, Buhl R, Mellem H, Hedman J, O'Neill S, Ekström T: Improved asthma control with budesonide/formoterol in a single inhaler, compared with budesonide alone. Eur Respir J 200I, 18:262-268.

II. Buhl R, Creemers JP, Vondra V, Martelli NA, Naya IP, Ekstrom T: Once-daily budesonide/formoterol in a single inhaler in adults with moderate persistent asthma. Respir Med 2003, 97:323-330.

12. Lalloo UG, Malolepszy J, Kozma D, Krofta K, Ankerst J, Johansen B, Thomson NC: Budesonide and formoterol in a single inhaler improves asthma control compared with increasing the dose of corticosteroid in adults with mild-to-moderate asthma. Chest 2003, I 23: | 480-1 487.

13. Bateman ED, Bantje TA, Joao Gomes M, Toumbis MG, Huber RM, Naya I, Eliraz A: Combination therapy with single inhaler budesonide/formoterol compared with high dose of fluticasone propionate alone in patients with moderate persistent asthma. Am J Respir Med 2003, 2:275-28I.

14. O'Byrne PM, Bisgaard H, Godard PP, Pistolesi M, Palmqvist M, Zhu Y, Ekstrom T, Bateman ED: Budesonide/formoterol combination therapy as both maintenance and reliever medication in asthma. Am J Respir Crit Care Med 2005, 17 I:129-136.

15. Rabe KF, Atienza T, Magyar P, Larsson P, Jorup C, Lalloo UG: Effect of budesonide in combination with formoterol for reliever therapy in asthma exacerbations: a randomised controlled, double-blind study. The Lancet 2006, 368:744-753.

16. Barnes PJ: A single inhaler for asthma? Am J Respir Crit Care Med 2005, I71:95-96.

17. Gibson PG: Teaching old drugs new tricks: asthma therapy adjusted by patient perception or noninvasive markers. Eur Respir J 2005, 25:397-399.

18. Rubinfeld AR, Scicchitano R, Hunt A, Thompson PJ, Van Nooten A, Selroos O: Formoterol Turbuhaler as reliever medication in patients with acute asthma. Eur Respir J 2006, 27:735-74I.

19. Balanag VM, Yunus F, Yang PC, Jorup C: Efficacy and safety of budesonide/formoterol compared with salbutamol in the treatment of acute asthma. Pulm Pharmacol Ther 2006, 19:139-147.

20. Bateman ED, Fairall L, Lombardi DM, English R: Budesonide/formoterol and formoterol provide similar rapid relief in patients with acute asthma showing refractoriness to salbutamol. Respir Res 2006, 7:13.

21. Standards for the diagnosis and are of patients with chronic obstructive pulmonary disease COPD) and asthma. This official statement of the American Thoracic Society was adopted by the ATS Board of Directors, November 1986. Am Rev Respir Dis 1987, 136:225-244.

22. Crapo RO, Casaburi R, Coates AL, Enright PL, Hankinson JL, Irvin CG, Maclntyre NR, McKay RT, Wanger JS, Anderson SD, Cockcroft DW, Fish JE, Sterk PJ: Guidelines for methacholine and exercise challenge testing-1999. This official statement of the American Thoracic Society was adopted by the ATS Board of Directors, July 1999. Am J Respir Crit Care Med 2000, 161:309-329.

23. Wilson RC, Jones PW: A comparison of the visual analogue scale and modified Borg scale for the measurement of dyspnoea during exercise. Clin Sci (Lond) 1989, 76:277-282. 
24. Kendrick KR, Baxi SC, Smith RM: Usefulness of the modified 010 Borg scale in assessing the degree of dyspnea in patients with COPD and asthma. J Emerg Nurs 2000, 26:216-222.

25. Quanjer PH, Tammeling G], Cotes JE, Pedersen OF, Peslin R, Yernault JC: Lung volumes and forced ventilatory flows. Report Working Party Standardization of Lung Function Tests, European Community for Steel and Coal. Official Statement of the European Respiratory Society. Eur Respir J Suppl 1993, 16:5-40.

26. van der Woude, Boorsma M, Bergqvist PB, Winter TH, Aalbers R: Budesonide/formoterol in a single inhaler rapidly relieves methacholine-induced moderate-to-severe bronchoconstricion. Pulmonary Pharmacology \& Therapeutics 2004, 17:89-95.

27. van der Woude HJ, Postma DS, Politiek MJ, Winter TH, Aalbers R: Relief of dyspnoea by beta2-agonists after methacholineinduced bronchoconstriction. Respir Med 2004, 98:816-820.

28. Scicchitano R, Aalbers R, Ukena D, Manjra A, Fouquert L, Centanni S, Boulet LP, Naya IP, Hultquist C: Efficacy and safety of budesonide/formoterol single inhaler therapy versus a higher dose of budesonide in moderate to severe asthma. Curr Med Res Opin 2004, 20:|403-14|8.

29. Vogelmeier C, D'Urzo A, Pauwels R, Merino JM, Jaspal M, Boutet $S$, Naya I, Price D: Budesonide/formoterol maintenance and reliever therapy: an effective asthma treatment option? Eur Respir J 2005, 26:819-828.

Publish with Bio Med Central and every scientist can read your work free of charge

"BioMed Central will be the most significant development for disseminating the results of biomedical research in our lifetime. "

Sir Paul Nurse, Cancer Research UK

Your research papers will be:

- available free of charge to the entire biomedical community

- peer reviewed and published immediately upon acceptance

- cited in PubMed and archived on PubMed Central

- yours - you keep the copyright
BiolMedcentral 